\title{
Rumah Singgah untuk Penderita Kanker dengan Konsep Healing Environment
}

\author{
Nathania Corry Clarissa dan Ima Defiana \\ Departemen Arsitektur, Fakultas Arsitektur, Desain dan Perencanaan, \\ Institut Teknologi Sepuluh Nopember (ITS) \\ e-mail: imadefiana1@gmail.com
}

\begin{abstract}
Abstrak-Kanker menjadi salah satu permasalahan kesehatan di Indonesia. Pengobatan kanker membutuhkan waktu yang lama dan mahalnya biaya pengobatan. Bagi penderita kanker asal luar Jakarta harus mengeluarkan biaya tambahan untuk transportasi maupun penginapan. Rumah singgah didesain untuk para penderita kanker yang berasal dari luar daerah Jakarta, yang sedang melakukan pengobatan atau menunggu jadwal kemoterapi di Rumah Sakit Kanker Dharmais. Rumah singgah mampu memberikan pengaruh positif pada proses penyembuhan bagi penderita kanker, dan menghadirkan interaksi sosial antar penderita kanker. Interaksi ini akan memberikan sebuah dukungan psikis. Sebuah teori yang menyatakan bahwa faktor lingkungan merupakan faktor yang paling berpengaruh dalam proses pengobatan dibandingkan dengan faktor medis. Oleh karena itu, rumah singgah dirancang dengan konsep healing environment agar dapat menciptakan lingkungan positif. Metode merancang dengan menggunakan metode Multi-Sensory Experience. Multi-Sensory Experience memberikan pengalaman sense seperti visual, pendengaran, peraba dan penciuman yang dapat memberikan efek healing bagi pengguna. Kriteria perancangan secara keseluruhan merujuk pada konsep healing environment. Dalam aspek arsitektur, rancangan dapat memperhatikan bentuk, sirkulasi, tata ruang dan perletakkan bukaan, pencahayaan, penghawaan, warna dan tekstur material. Aspek non-arsitektural dapat dihadirkan melalui rancangan taman merujuk pada kriteria healing garden. Sebuah hasil penelitian bahwa suara alam, alam terbuka dengan suasana hijau dapat memberikan dampak positif bagi pikiran dan tubuh walau hanya beberapa menit.
\end{abstract}

Kata Kunci-Experience, Interaksi, Multi Sensory.

\section{PENDAHULUAN}

K ETERBATASAN fasilitas dan tenaga kesehatan yang kurang memadai memaksa penderita kanker dari luar daerah Jakarta datang berobat ke Jakarta. Selain itu, proses pengobatan yang membutuhkan waktu lama serta biaya rawat inap yang mahal menjadi beban tambahan bagi pasien kanker. Beberapa yayasan peduli kanker telah berusaha merespon permasalahan tersebut dengan mendirikan rumah singgah. Bangunan rumah singgah tersebut tidak dirancang sesuai kebutuhan melainkan bangunan rumah tinggal dua lantai yang kemudian diubah fungsi menjadi rumah singgah dimana kondisi lingkungannya dirasa kurang mampu memberikan dampak positif terhadap proses penyembuhan penderita kanker (Gambar 1).
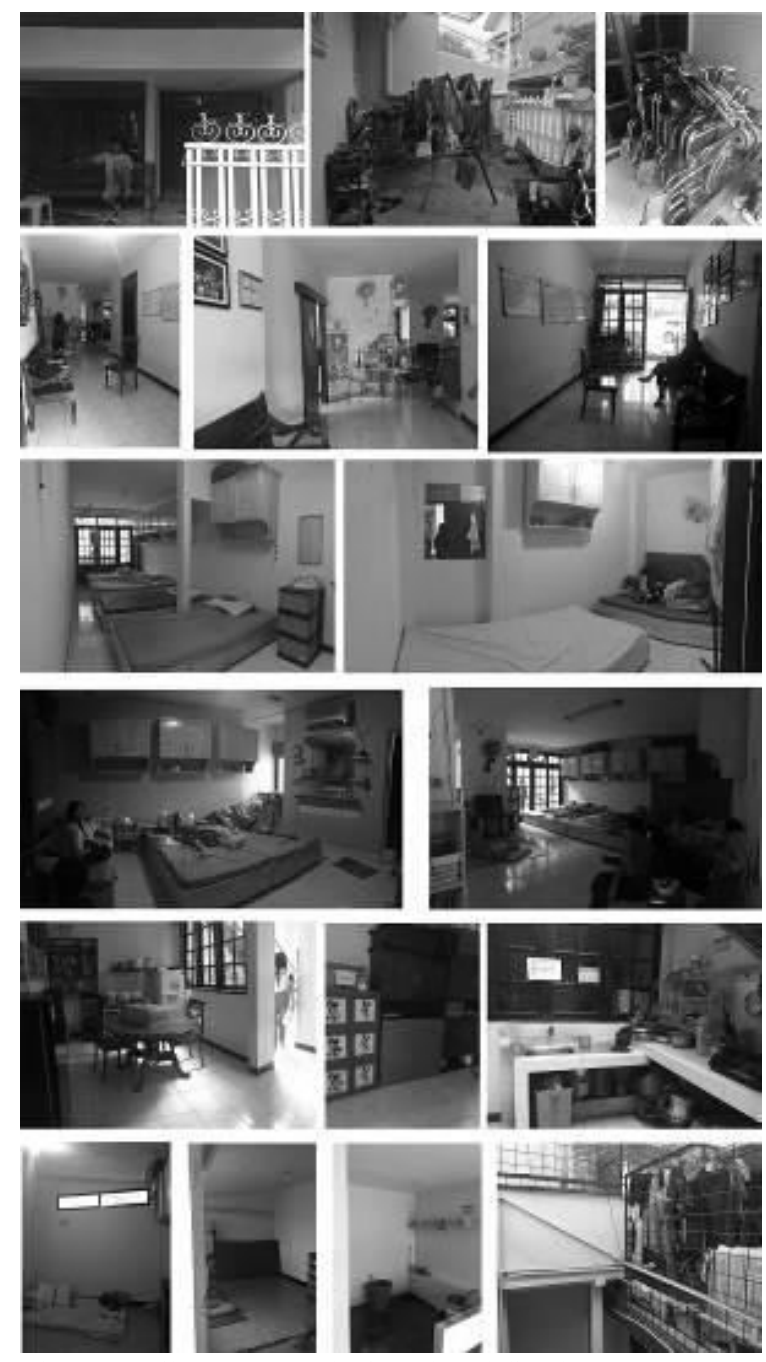

Gambar 1. Hasil survey Rumah Singgah Peduli, Jakarta Barat.

Sebuah teori menyebutkan bahwa ada beberapa faktor yang berpengaruh dalam proses kesembuhan, yakni : Faktor Lingkungan (40\%), Faktor Medis (10\%), Faktor Genetis (20\%), dan Faktor Lainnya (10\%) [1]. Bila dilihat dari teori diatas bahwa faktor lingkungan merupakan faktor yang paling berpengaruh dalam proses pengobatan dibandingkan dengan faktor medis. Presentase faktor lingkungan yang besar tersebut mendukung penggunaan pendekatan healing environment pada rumah singgah. 


\section{KONTEKS DESAIN}

\section{A. Lokasi Perancangan}

Lokasi terletak di Jalan Anggrek Neli Murni, Kemanggisan, Palmerah, Kota Jakarta Barat. Lokasi ini terletak di tengah perumahan dan perkantoran. Lahan eksisting merupakan lahan perumahan yang memiliki luas sekitar $9.960 \mathrm{~m}^{2}$ (Gambar 2 dan 3).

\section{B. Sasaran Pengguna}

Sasaran pengguna rumah singgah diutamakan penderita kanker yang berasal dari luar Jawa dengan golongan ekonomi menengah kebawah. Penderita kanker bersama pendamping dapat tinggal di rumah singgah yaitu kurang lebih 2-3 minggu. Waktu tersebut berdasarkan kebutuhan rata-rata penderita kanker memulihkan kondisi fisik sebelum melakukan tindakan kemoterapi selanjutnya.

Program aktivitas kemudian dikelompokan berdasarkan zona ruang masing-masing aktivitas. Hasilnya terdapat 6 zona area pada objek sebagai berikut:

1. Area Penerimaan

2. Area Perawatan non medis

3. Area Perawatan medis

4. Area Perkantoran

5. Area Servis

Alur aktivitas disesuaikan dengan pelaku dan zona terhadap aktivitas yang dilakukan (Gambar 4).

\section{PENDEKATAN DAN METODE DESAIN}

\section{A. Pendekatan Desain}

Healing environment adalah lingkungan fisik fasilitas kesehatan yang dapat mempercepat waktu pemulihan keseha tan pasien atau mempercepat proses adaptasi pasien dari kondisi kronis serta akut dengan melibatkan efek psikologis pasien di dalamnya [2]. Pendekatan healing environment didapatkan melalui perpaduan pendekatan architectural healing environment dan healing garden yang terintegrasi (Gambar 5).

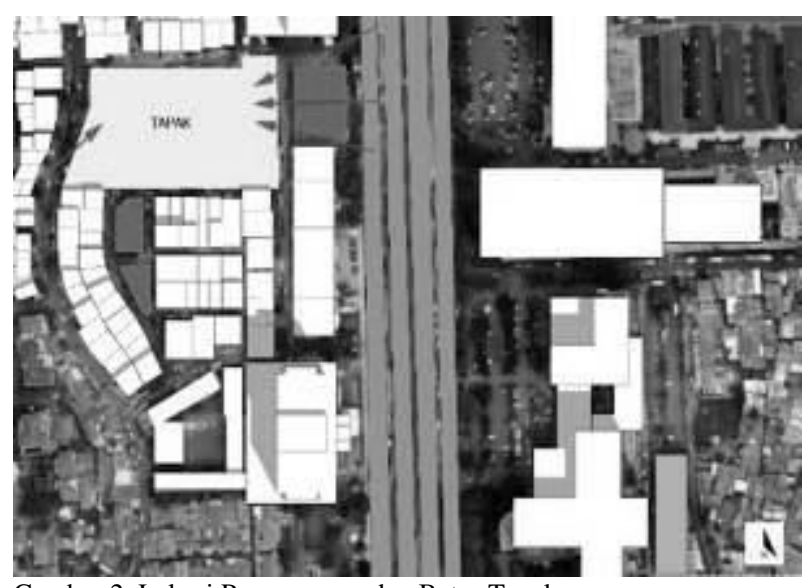

Gambar 2. Lokasi Perancangan dan Batas Tapak.

Architectural healing environment fokus pada arsitektur sebagai bagian dari sebuah lingkungan terapetik yang dapat memberikan dampak pada proses penyembuhan. Sedangkan healing garden menjadi aspek hadirnya alam didalam lingkungan terapetik tersebut yang dapat dirasakan pengguna secara langsung melalui indra. Hal tersebut dikarenakan adanya hasil penelitian oleh Brighton and Sussex Medical School, menyatakan bahwa ada aktivitas di jaringan mode bawaan otak. secara keseluruhan, suara alam meningkatkan respons parasimpatis yang membuat tubuh rileks dan berfungsi dalam keadaan normal, disebut sebagai rest-digest respon.

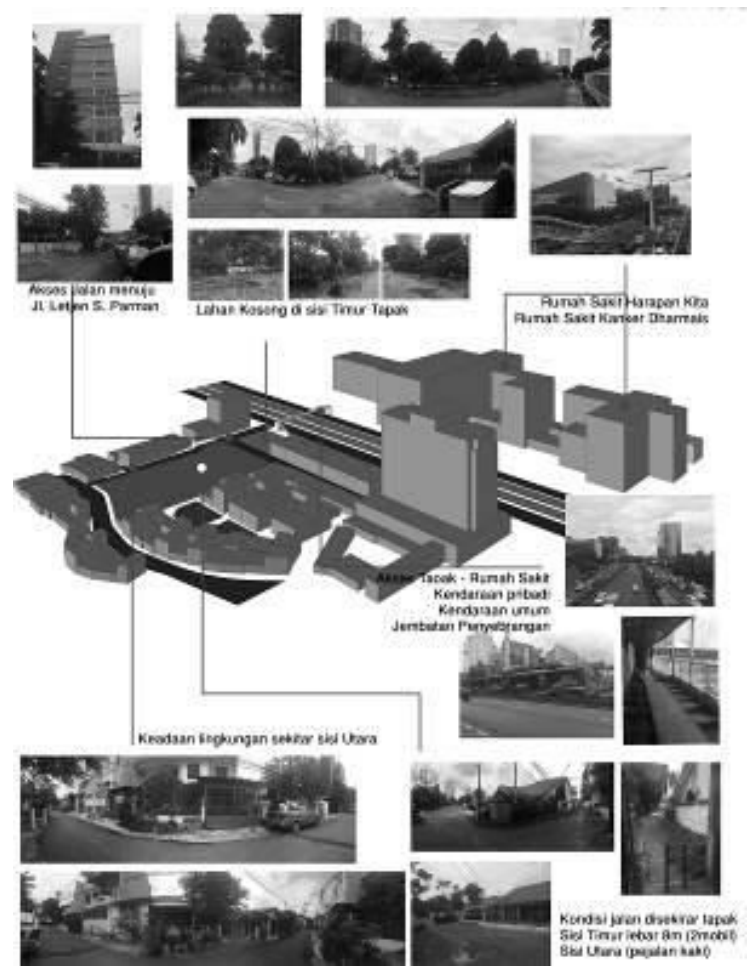

Gambar 3. Keadaan Lingkungan Sekitar Tapak.

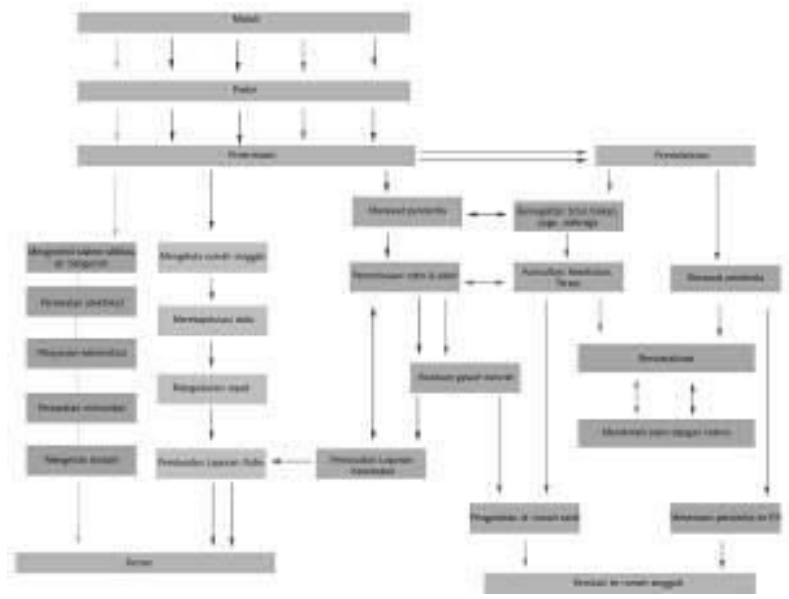

Gambar 4. Alur Aktivitas Pada Desain Rumah Singgah.

Pendekatan home-like environment dan biophilic design sebagai teori pendukung pada perancangan. Desain Biophilik adalah sebuah bangunan yang mampu menyelaraskan kepentingan alam dan manusia [3]. Pengertian home-like environment adalah timbulnya perasaan seperti dirumah. Suasana berada seperti dirumah akan membuat pengguna merasa nyaman. Salah satu cara menciptakan suasana homey adalah dengan membangun hubungan antara seseorang dengan 
lingkungannya. Kriteria desain yang meliputi, zoning, tatanan massa, sirkulasi, bentuk, dan material juga merujuk pada kedua pendekatan tersebut (Gambar 6).

\section{B. Metode Desain}

Pendekatan indra dalam mendesain healing environment mendukung penggunaan metode Multi Sensory Experience dalam menyelesaikan permasalahan desain. Multi sensory experience memberikan pengalaman sensoria baik secara visual, pendengaran, perabaan maupun penciuman yang dapat memberikan efek healing. Setiap pengalaman dalam arsitektur melibatkan hampir semua indra [4]. Sebuah arsitektur dapat diingat karena arsitektur tersebut mempengaruhi tubuh dan indra manusia sehingga membangkitkan hubungan pribadi masing-masing manusia. Metode Multi Sensory Experience bertujuan untuk memberikan pengalaman sensoria baik secara visual, pendengaran, perabaan maupun penciuman yang dapat memberikan efek healing (Gambar 7).

Aroma yang menenangkan dapat menurunkan tekanan darah dan detak jantung, sedangkan bau yang tidak sedap dapat meningkatkan detak jantung dan pernapasan. Pengalaman sensoria penciuman menjadi metode dalam menghadirkan aromaterapi pada bangunan seperti meletakkan tanaman aromatherapy disekitar massa bangunan dan didekat sirkulasi didalam healing garden.

Pengalaman sensoria penglihatan menjadi metode dalam merancang konsep visual pada bangunan. Visual dapat mempengaruhi psikologi manusia, contohnya pemandangan, cahaya alami, karya seni dan penggunaan warna tertentu dapat membuat mata menjadi santai seperti. Hal tersebut dapat diaplikasikan pada ruangan dengan membuat akses untuk melihat alam melalui kehadiran bukaan yang besar kearah healing garden.

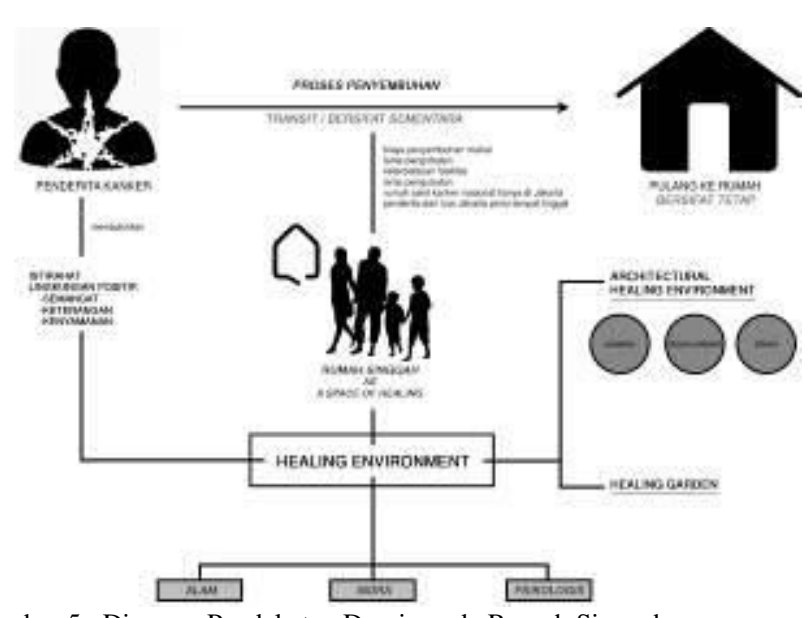

Gambar 5. Diagram Pendekatan Desain pada Rumah Singgah.

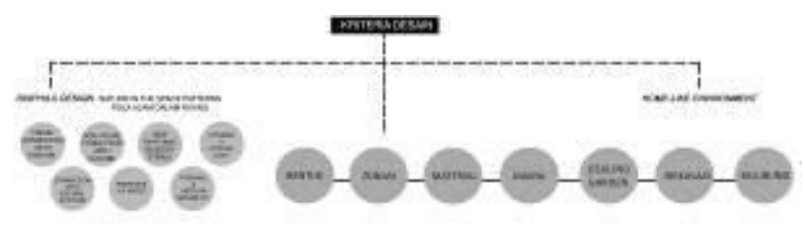

Gambar 6. Diagram Kriteria Desain.

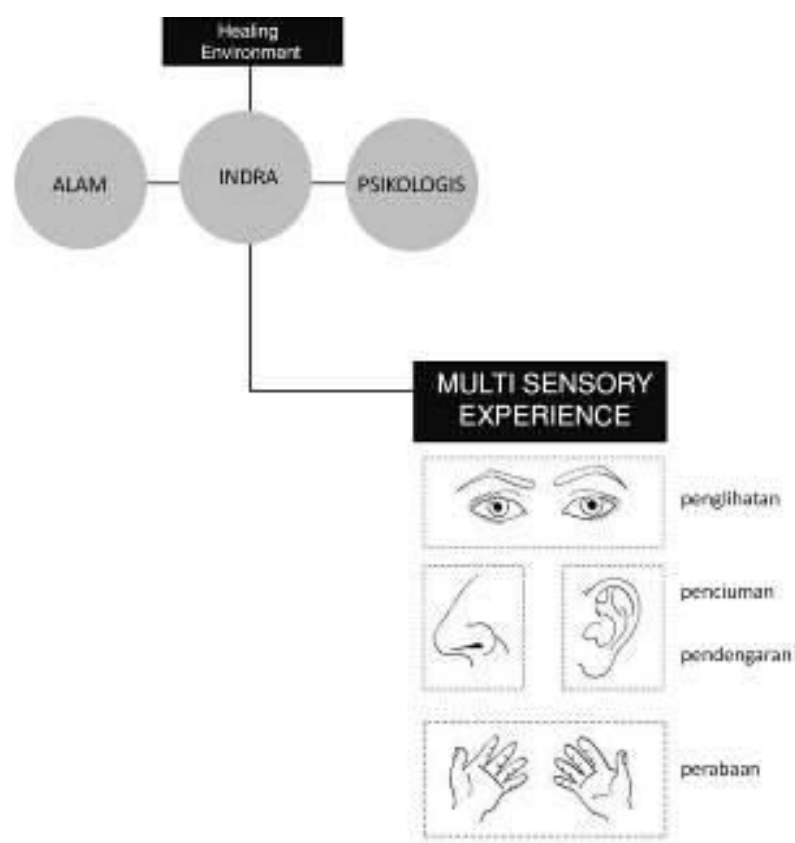

Gambar 7. Penerapan Metode Multi Sensory Experience.

Sentuhan merupakan mekanisme dasar dalam menjelajahi dunia karena sentuhan menegaskan apa yang mereka lihat, cium, rasa dan dengar. Pengalaman sensoria perabaan menjadi metode dalam menentukan tekstur seperti penggunaan material alam yang memiliki tekstur alami, pemilihan tekstur furniture.

Pengalaman sensoria pendengaran seperti menjadi metode dalam merancang konsep akustik seperti suara gemiricik yang menenangkan melalui kehadiran kolam dengan air yang terus mengalir. Suara yang menyenangkan dapat menenangkan pikiran.

\section{EKSPLORASI DESAIN}

\section{A. Tatanan Massa}

Menghadirkan tatanan multi-massa pada rancangan dengan metode spread. Hal tersebut untuk mendukung terciptanya suasana home-like environment agar pengguna tetap merasa nyaman seperti berada dilingkungan rumah serta mendukung adanya interaksi sosial (Gambar 8).

Pada Gambar terkait rancangan siteplan terlihat perpaduan bentukan bangun dan elemen landscape seperti rumput, kolam, taman dengan beragam jenis vegetasi dan elemen landscape lainnya disekitar bangunan. Rancangan siteplan memperhatikan potensi lingkungan sekitar. Terdapat beberapa jenis massa bangunan yang ada pada kawasan dengan mempertimbangkan konsep massa dan konsep zonasi horizontal sebagai berikut:

- Fasilitas penerimaan meliputi area penerimaan

- Fasilitas hunian meliputi area hunian dan terdapat juga ruang terapi bagi penderita kanker seperti ruang fisioterapi, imunoterapi.

- Fasilitas penunjang mendukung terkait aspek psikologis.

- Fasilitas pengelolaan sebagai area kerja pengelola.

- Fasilitas pendukung yaitu area servis dan r. serbaguna

- Fasilitas utilitas terkait aspek utilitas listrik dan air 
Penataan massa merujuk pada konsep zonasi vertikal yang menyesuaikan kebutuhan fungsi, sifat kegiatan dan pelaku (Gambar 9). Ruang terbuka hijau menjadi pusat penataan massa. Adanya spasial antar massa yang difungsikan sebagai bagian dari sirkulasi ruang luar yang mendukung hadirnya taman. Pergerakan sirkulasi udara didalam tapak menjadi lebih baik karena adanya spasial antar massa.

\section{B. Bentuk}

Bentuk dasar bangunan mengutamakan sudut yang terbentuk dari perletakkan taman yang ada disekitar tapak, menyesuaikan taman eksisting disekitar tapak agar tercipta visual taman yang lebih luas dan menerus. Oleh karena itu, garis lengkung pada taman eksisting diteruskan pada tapak. Garis lengkung memberi kesan dinamis, mendorong orang bergerak dan menghindari suasana statis (Gambar 10).

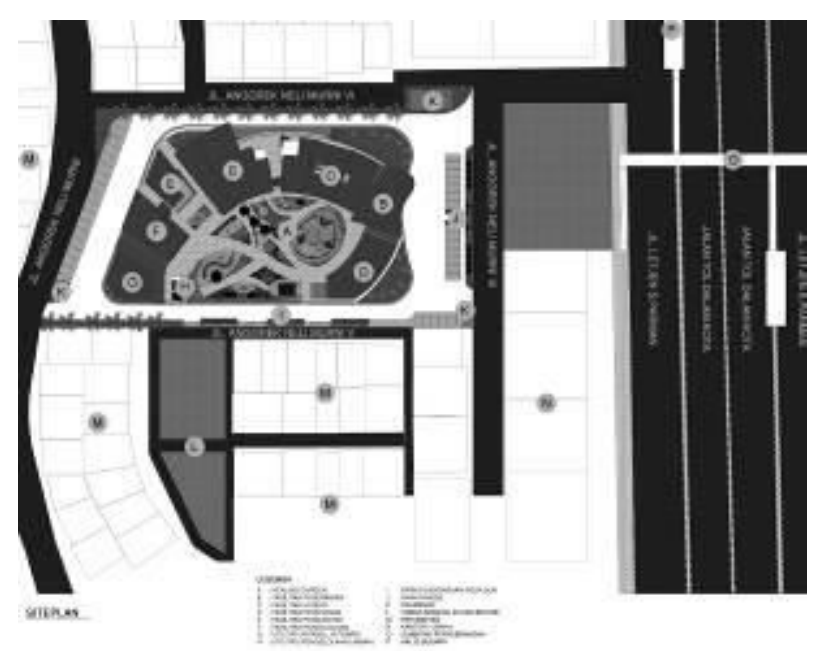

Gambar 8. Siteplan

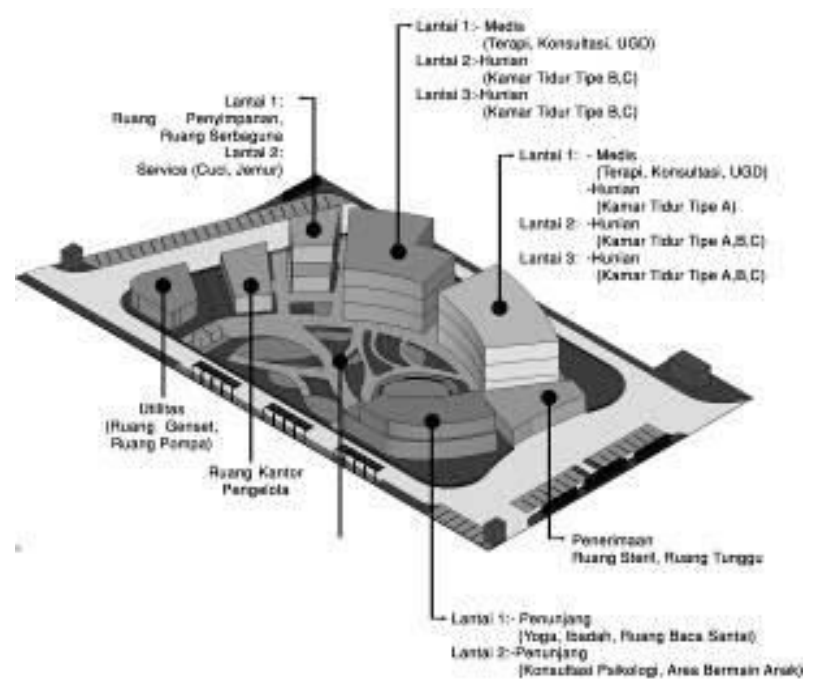

Gambar 9. Konsep Zonasi Vertikal.

\section{Warna dan Tekstur Material}

Warna merupakan salah satu faktor yang mempengaruhi persepsi seseorang dalam mengartikan sebuah ruang. Setiap warna dapat memberikan suatu efek psikologis pada masingmasing orang.

Rancangan menggunakan material alam pada elemen tertentu disesuaikan dengan kebutuhan dan persyaratan ruang (Gambar 11). Pada beberapa bagian, batu bata disusun secara zig-zag dan di biarkan berongga. Batu bata merupakan material yang umum dijumpai pada lingkungan rumah yang dapat memberi kesan sederhana, nyaman, yang mendukung pendekatan home-like environment.

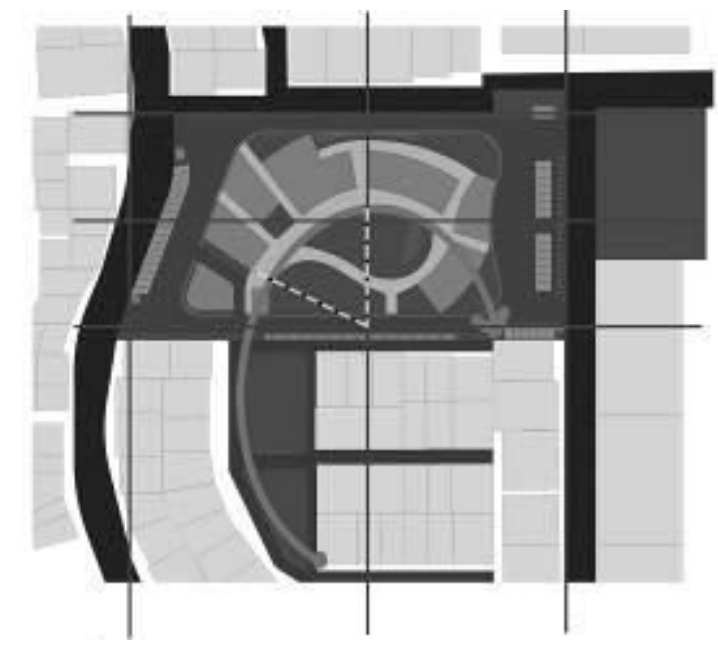

Gambar 10. Konsep Ide Bentuk

\section{Healing Garden}

Healing garden menurut Marni Barnes adalah sebuah taman yang dapat meredakan gejala stres seseorang. Pada rancangan terdapat taman yang dapat diakses secara visual dari berbagai zona dan massa bangunan. Pemilihan vegetasi pada area taman merujuk terkait setiap indra yang dimiliki setiap orang (Gambar 12). Selain indra penglihatan dengan melihat vegetasi secara visual dari aspek estetika, berbagai jenis vegetasi pada taman juga memperhatikan indra penciuman dengan menggunakan aroma dari berbagai tanaman bunga (Gambar 13).

\section{E. Interior}

Konfigurasi ruang dalam pada fasilitas penerimaan meliputi ruang tunggu, ruang steril dan toilet (Gambar 14). Ruang tunggu dapat menentukan kesan pertama terhadap rumah singgah. Kesan home-like environment dihadirkan pada bangunan ini, agar pengunjung sejak awal memasuki rumah singgah dapat merasakan suasana nyaman seperti berada dirumah. Celah pada dinding batu bata expose apabila terkena sinar matahari akan memberikan efek bayangan yang menarik pada interior (Gambar 15).

Konfigurasi ruang pada fasilitas hunian meliputi ruang yang menyesuaikan dengan kegiatan sehari-hari dan ruang terapi (Gambar 16). Ruang tidur merupakan area yang krusial. Warna hijau banyak digunakan pada ruangan ini karena hijau dapat memberikan rasa nyaman, dan stress-relieving. (Gambar 17). Pada interior dapur dan ruang makan, terlihat adanya bukaan yang lebar sehingga pengguna rumah singgah dapat menikmati pemandangan healing garden Selain itu, dinding batu bata berongga juga dihadirkan untuk mendukung sirkulasi udara pada ruangan (Gambar 15 dan17). Dinding pada ruang 
fisioterapi menggunakan warna turqoise, perpaduan warna hijau dan biru. Warna turqoise dapat meningkatkan imunitas tubuh. Aksen kayu dan warna netral lebih digunakan pada dinding ruang imunoterapi. Suasana yang professional dihadirkan pada ruang terapi agar pengguna akan merasa yakin dengan fasilitas (Gambar 18).

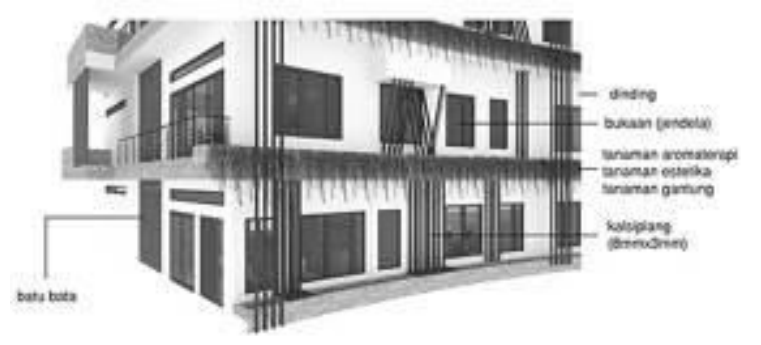

Gambar 11. Penggunaan Material Alam pada Fasad

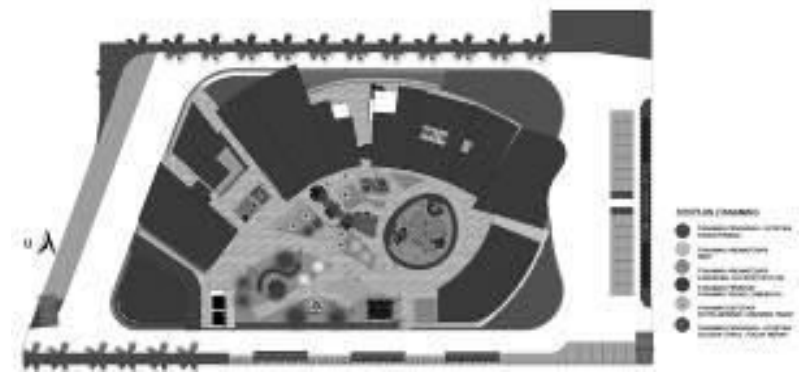

Gambar 12. Perletakkan Vegetasi pada Healing Garden

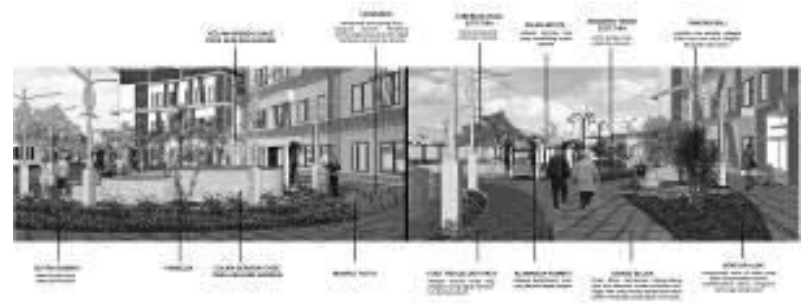

Gambar 13. Jenis Vegetasi pada Healing Garden.

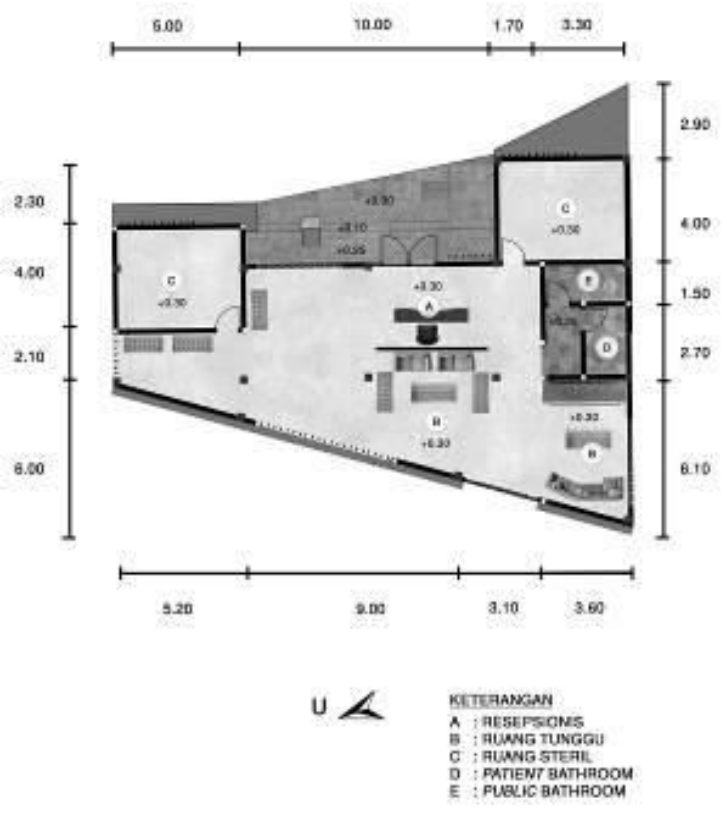

Gambar 14. Denah Fasilitas Penerimaan.

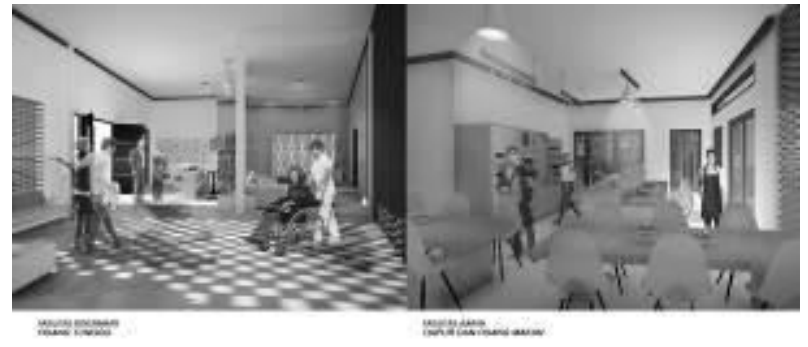

Gambar 15. Perspektif Interior Fasilitas Penerimaan dan Hunian
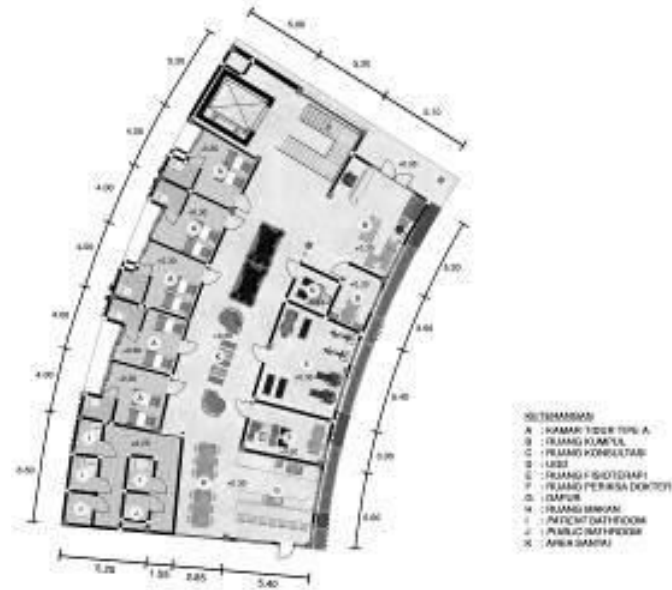

Gambar 16. Denah Fasilitas Hunian.

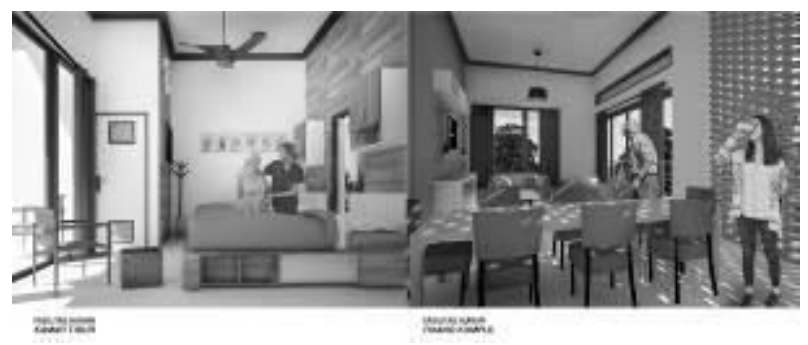

Gambar 17. Perspektif Interior Fasilitas Penerimaan dan Hunian.

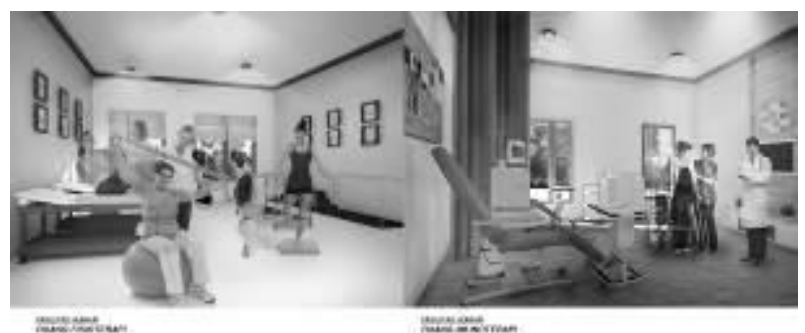

Gambar 18. Perspektif Interior Ruang Terapi.

\section{KESIMPULAN}

Objek arsitektur ini bertujuan sebagai tempat tinggal sementara bagi penderita kanker yang berasal dari luar Jawa yang sedang menjalani masa pengobatan di Rumah Sakit Kanker Dharmais. Berdasarkan kajian teori, faktor lingkungan memiliki pengaruh besar dalam proses penyembuhan seseorang.

Oleh sebab itu, kehadiran rumah singgah dengan konsep healing environment diharapkan mampu menciptakan sebuah lingkungan positif yang dapat memberikan kenyamanan, ketenangan dan pengaruh positif lain melalui aspek arsitektur dengan memperhatikan bentuk, sirkulasi, tata ruang dan 
perletakkan bukaan, pencahayaan, penghawaan, pemilihan warna dan tekstur material. Rumah singgah diharapkan dapat memberikan kontribusi positif terhadap kesehatan penderita kanker.

\section{DAFTAR PUSTAKA}

[1] R. M. Kaplan, J. J. F. Sallis, and T. L. Patterson, Health and Human Behaviour. New York: Mc Graw Hill Book Co., 1993.
[2] K. Dijkstra, "Understanding Healing Environments: effects of physical environmental stimuli on patients' health and well-being," Enschede, 2009.

[3] S. R. Kellert, Building for Life: Designing and Understanding the Human-Nature Connection. United State of America: Island Press, 2005.

[4] J. Pallasmaa, The Eye of the Skin. New York: John Wiley \& Sons, 1996. 